\title{
El léxico del dialecto chileno: Diccionario de uso del español de Chile DUECh
}

\author{
The lexicon of Chilean Spanish: Dictionary of Chilean Spanish usage
}

\section{Leopoldo Sáez Godoy}

Universidad de Santiago de Chile, Santiago, Chile; Correo electrónico: leopoldosaez@gmail.com

\begin{abstract}
No hay un patrimonio cultural más importante que la lengua de una comunidad nacional. Un diccionario dialectal es una obra de gran trascendencia social. Aunque no se pretenda, siempre adquiere un valor normativo. Para el que lo consulta, las definiciones que encuentra representan una verdad indiscutible, más aún cuando ha sido elaborado por una entidad de prestigio y está avalado por importantes instituciones culturales. El DUECh es el más reciente recuento de esta naturaleza. En el artículo se discuten algunos criterios de selección de lemas. Se pone a prueba la recolección mediante sondeos en el vocabulario de la vida social y política, en locuciones verbales, en procedimientos de creación de neologismos: acrónimos, aposición $\mathrm{S}+\mathrm{S}$ y $\mathrm{S}+\mathrm{Adj}$, compuestos $\mathrm{V}+\mathrm{S}$. Para algunos lemas, se discuten las definiciones parcial o totalmente y se proponen otras acepciones, homónimos y variantes.
\end{abstract}

Palabras clave: dialectología, español de Chile, lexicología, lexicografía, diccionarios.

There is no cultural patrimony more important than the language of a national community. A dialectal dictionary is a work of great social significance. Even if one does not want it, it always gets a normative value. For the user, its definitions amount to an undebatable truth. More so if it has been produced by a prestigious entity and is indorsed by important cultural institutions. The DUECh is the latest inventory of this kind. This article discusses some of its criteria for selecting lemmas. Collection by means of some surveys is put to test: vocabulary of social and political life, verbal phrases, procedures for the creation of neologisms (acronyms, $\mathrm{N}+\mathrm{N}$ and $\mathrm{N}+$ Adj. appositions, $\mathrm{V}+\mathrm{N}$ compounds). Some of the partially or totally debatable definitions are analyzed and other meanings, homonyms and variants are proposed.

Key words: lexicology, lexicography, dialectology, chilean spanish, dictionaries.

\section{INTRODUCCIÓN}

No hay un patrimonio cultural más importante que la lengua que hablamos, que hemos heredado y vamos renovando de generación en generación. Un diccionario dialectal es una obra de una trascendencia social incomparablemente superior a 
una investigación lingüística cualquiera. Aunque no se pretenda, inevitablemente adquiere un valor normativo. Para el que lo consulta, que no suele ser lingüista, las definiciones que encuentra representan una verdad indiscutible, más aún cuando el responsable de la publicación es una entidad de prestigio y recibe el apoyo de importantes instituciones culturales. Desde la partida, me parece justo tener presente que es muchísimo menos trabajoso criticar un diccionario que construirlo.

Luego de diez largos años de trabajo, en 1978, la Academia Chilena de la Lengua (AChL) publicó un Diccionario del Habla Chilena (Academia Chilena de la Lengua 1978). Desgraciadamente, el resultado distó mucho de ser satisfactorio: ${ }^{1}$ fuentes insuficientes y mal aprovechadas, muchas definiciones erróneas, cientos de omisiones importantes (Saéz Godoy 1982: 114), bibliografía incompleta y errores de todo tipo, desorden alfabético e incluso faltas de ortografía. En suma, un trabajo en extremo descuidado que no estaba al nivel de la lexicografía de la época ni de nuestra larga tradición en este campo.

El proyecto de la AChL era refundir "en un solo volumen, el material lexicográfico de los diccionarios antiguos” (DHCh 1978: 17) e incluir “...todo el material léxico que registra el Diccionario de la Academia como de uso en Chile” (20). No se hizo bien ni lo uno ni lo otro. Así la AChL había quedado en deuda con una obra que no está en consonancia con el prestigio de los connotados miembros de la Comisión de Lexicografía (Oroz, Lira Urquieta, Pino Saavedra, Pereira Salas, Gunckel, Matus Olivier...), responsables finales de la publicación.

No obstante, el Diccionario de Uso del español de Chile (DUECh), publicado en 2010, sube a un nivel más aceptable. La presentación es muy grata. Tapa dura, tipografía clara y legible sin esfuerzo. No se ha mezquinado el espacio. El texto aparece prácticamente sin erratas ni errores ortográficos ${ }^{2}$, hecho muy poco habitual en nuestro medio editorial. Ya no pretende ser una suerte de Thesaurus amplísimo, sin límites en el tiempo, en el espacio, en los niveles sociolingüísticos, en los estilos. Los objetivos son ahora muy razonables. En estos treinta años, por cierto, la investigación lexicológica y lexicográfica no se ha detenido. En Chile, Morales Pettorino y su equipo han trabajado incansablemente y han puesto en otro nivel la investigación sobre el léxico del español de Chile. En 1983, apareció el Diccionario Ejemplificado de Chilenismos. Estudio Preliminar. En 1984 el primero de los cuatro tomos del Diccionario Ejemplificado de Chilenismos y de otros usos diferenciales del español de Chile (DECh). Los siguientes en 1985, 1986 y 1987 y el quinto —una revisión de los cuatro primeros_ - en 1998, once años más tarde. En 2006, aparecieron los tres tomos del Nuevo Diccionario Ejemplificado de Chilenismos y de otros usos diferenciales del español de Chile (NDECh). Actualmente con el Nuevo Diccionario Ejemplificado de Chilenismos. Edición refundida y actualizada. Suplemento (2010) llegan a diez los tomos con 11.322 páginas. ${ }^{3}$ Se han ampliado las fuentes, el repertorio

Para citar sólo algunos casos: no aparecen voces tan características del español de Chile como hueva, hueveo, huevear, huevón (ésta sólo parcialmente aparece en la acepción de "tonto, torpe”), cabro, rajazo, chapalele... Véase el detalle en las reseñas-artículos de Carrillo (1981), Sáez Godoy (1982) especialmente para lo relacionado con la ingesta alcohólica, campo muy amplio en nuestro dialecto, la esfera sexual, las comidas, la caracterización del hombre, voces regionales de Chiloé, etc., y Sáez Godoy (1987-1988) para definiciones que podrían mejorarse.

2 El vistoso "tuvo (sic) adherido al muro del baño..." (746) es excepcional en el texto. También lo es el desorden alfabético de perraje, perrear, perra, perro...

3 Morales Pettorino (1984-1998, 2006, 2010). La obra ha recibido importantes distinciones: en 1981, la guía teórica 
léxico incorporado ha crecido enormemente, se ha refinado la caracterización de las unidades léxicas y se ha llegado a una ejemplificación total. ${ }^{4}$

Por otra parte, la Real Academia está muy lejos de las hermosas fichas manuscritas que nos mostraba con sumo cariño don Rafael Lapesa. A esta transformación no es ajeno el apoyo económico de la Fundación pro Real Academia Española, sucesora desde 1993 de la Asociación de Amigos de la Real Academia Española. A ella pertenecen Juan Carlos I, representantes de los gobiernos, Juntas, Generalidades, comunidades, diputaciones, principados; bancos (de España, Bilbao, Vizcaya, Santander, Popular Español), Cajas de Ahorro, Telefónica, Fundaciones, Espasa Calpe, Anaya, Corte Inglés, International. Se han creado bancos de datos lingüísticos y un Instituto de Lexicografía. Han cambiado la práctica y la teoría lexicográficas. Se suceden los diccionarios: generales, esenciales, de dudas y, para nuestro caso especialmente importante, de americanismos (Asociación de Academias 2010). ${ }^{5}$ En palabras de la propia entidad autora, "El diccionario de 1978 ha quedado ya como una muestra de lo que fue la lexicografía del pasado con todas sus fragilidades y —por qué no decirlo— sus prevaricaciones” (Matus 2010: 5). Pero hay que recordar que el DUECh fue precedido en 2001 por una Muestra Lexicográfica de mil unidades léxicas univerbales, un avance preparatorio de la edición de 2010.

\section{DESCRIPCIÓN}

La obra está concebida como "modular que va incrementando paulatinamente su repertorio" (Matus 2010: 6), en tanto "perfectible”6. Diccionario en orden alfabético recto (ch y ll están inmersos en c y l, respectivamente), monolingüe, semasiológico, descriptivo, diferencial (hay voces que no pertenecen al español panhispánico7), "incluye unidades léxicas vigentes en el español actual de Chile” (aunque no exclusivamente) de los últimos 60 años. También "se propone reflejar el uso corriente, socialmente estabilizado, de las unidades léxicas del español de nuestro país” (7). El corpus (1950-2010) es muy variado: textos periodísticos, literarios, radiales, televisivos, electrónicos, guiones cinematográficos.

El DUECh constata "el hecho de que una palabra [que] haya sido registrada en el diccionario no significa su legitimación (su empleo indiscriminado)" (9); "se concibe

del diccionario, el Estudio Preliminar, recibió el Premio del Consejo de Rectores de las Universidades Chilenas, mención Gramática, Concurso Bicentenario del Nacimiento de Andrés Bello; en 1983, la Real Academia Española le adjudicó el concurso Conde de Cartagena, abierto en mayo de 1979.

4 En el DUECh trabaja un numeroso equipo dirigido por Alfredo Matus Olivier: seis lingüistas de la Comisión de Lexicografía de la AChL y siete colaboradores. Recibió apoyo de la Dirección de Bibliotecas, Archivos y Museos, del Consejo Nacional del Libro y la Lectura, de la Asociación de Academias de la Lengua Española, de MN Editorial.

5 Sin olvidar, entre otros, los macizos trabajos de Günther Haensch y de Reinhold Werner en la U. de Augsburg y los de Luis Fernando Lara del Colegio de México.

6 “La Academia Chilena agradece (...) cualquier observación que permita enriquecer el caudal léxico de su diccionario y mejorar su calidad” (7).

7 Como, a veces, los diccionarios que constituyen "la base de contrastividad" del DUECh no incluyen todas las voces generales, como neologismos y extranjerismos “... el lector podría, eventualmente, encontrar en el DUECh entradas léxicas del español general” (8). También pueden existir diferencias de uso, registro y frecuencia que justifican su inclusión.

8 No aparece una justificación de la extensión ni de los límites de este período. 
principalmente como una herramienta de consulta para comprender textos escritos y orales” (9), pero también debiera entregar variada información que permita producir textos en nuestro dialecto, aunque este fin lo cumpliría mejor un diccionario onomasiológico.

Las locuciones y expresiones complejas tienen artículos independientes. Sus lemas están ordenados por una palabra clave: el primer V., S., ADJ. o ADV. que aparezca en la unidad léxica. Los homónimos también tienen artículos independientes, numerados y en orden de frecuencia o relevancia. Van en un mismo artículo cuando los significados están muy relacionados (metonimias, metáforas, variantes, diferencias de matices, entre otros). Así cada artículo puede constar de los siguientes elementos: lema; procedencia de los préstamos primitivos (se indica la lengua extranjera, pero no el étimo), de los substantivos comunes originados en una marca comercial (confort) o de una inversión (rati); categoría gramatical; marca de valoración social (vulgar, euf.); indicaciones de uso (empleo más frecuente en grupos específicos de la comunidad, en alguna variedad de habla, ámbito); definición (más de 9.000, en calidad de lingüísticas, no enciclopédicas; a menudo se incluye un equivalente panhispánico); marca geográfica (Norte, Centro, Sur, Zona Austral ${ }^{9}$ ); marca de estrato social ( cult.); marca de estilo o registro (espon., esm.); marca de intención (fest., desp., afec.); marca cronológica (obsol., hist.); marca de frecuencia (p. us.); observaciones de carácter complementario: gramaticales, fonéticas, combinaciones frecuentes; ejemplos para cada unidad léxica (salvo los gentilicios) y para cada significado ejemplos provienentes de fuentes escritas (en papel o electrónicas) y orales (radio y televisión); variantes morfológicas, fonéticas, gráficas; expresiones de las que forma parte la unidad léxica analizada.

\section{LA LECTURA}

Leer un diccionario de dialectalismos como el DUECh puede convertirse en un recorrido por la historia personal. De mi niñez reencontré los digüeñes, los changles, el pan francés, los cinco minutos, los temidos cueros del Bío Bío. Recordé las exhortaciones maternas a no andar desguañangado y no ser ayecagüe, a mis compañeros de liceo (público, gratuito y de calidad), especialmente al Chingue y al Pitra ${ }^{10}$, apodos inclementes. Con ellos jugábamos a la troya, al hachita y cuarta, al paco ladrón (algunos eran sumamente maulosos). Luego, mi relación con el pan batido, la salida de cancha con las insignias caturras, las dietéticas chorrillanas; más tarde, conocí los nivelays, gamelas, los tiburones y el marcial pasar número.

El DUECh recoge léxico muy variado. Mucho lenguaje juvenil y popular que aparece especialmente en la prensa, en blogs y foros de Internet. Así sobre clubes de fútbol: aurinegros, celestes, oro y cielo, albicelestes, albiverdes, albirrojos, papayeros, cruzados, albos, cementeros, autobuseros, bohemios, guata amarilla, zorros del desierto, chunchos, leones, canarios, potros, caturros (pero no los panzers). También se recoge mucho léxico rural, flora y fauna, gentilicios, voces de origen indígena.

\footnotetext{
Norte: Región de Arica y Parinacota y R. de Atacama; Centro: de la R. de Coquimbo a la del Libertador General B. O’Higgins; Sur: de la R. del Maule a la R. de Los Lagos; Zona Austral: de la R. C. Ibáñez del Campo a la R. de Magallanes y de la Antártica chilena. 
Los diccionarios dialectales indirectamente reflejan las características de la sociedad. Así, por ejemplo, algún indicio sobre nuestra idiosincrasia podría obtenerse de la abundancia de expresiones como agarrar para el chuleteo/ el leseo/ el columpio/ el fideo/ el hueveo/ el palanqueo/ el tandeo/la palanca, palanquear. El lector común y corriente que espere encontrar en un diccionario de este tipo sólo voces populares y rurales, lenguaje del hampa, jergas y vulgarismos de todo tipo, se sorprenderá al enterarse de que voces que atribuía al español estándar no lo son. Por ello muchas no están incorporadas al DRAE o, si lo están, llevan alguna marca, o bien tienen en Chile algunas particularidades que las diferencian del uso general panhispánico: edecán, encargatoria (de reo), estelar, faldeo, escalamiento, folletería, entumirse, fonoaudiología, hiperquinesis, implicancia, leva, liceano, maleza, manubrio, marina, piño, postnatal, postítulo.

En la introducción Alfredo Matus cita al lexicógrafo inglés Samuel Johnson quien describe certeramente este tipo de trabajos: "Los diccionarios son como los relojes: el peor es mejor que ninguno, pero del mejor no se puede esperar que sea del todo preciso" (2010: 5-10). Johnson calla modestamente la cantidad de trabajo y la variedad de conocimientos y competencias que demanda una obra de esta naturaleza. De los manicomios solía decirse que en ellos "no están todos los que son, ni son todos los que están”. Algo similar puede sostenerse, en general, respecto de los diccionarios.

\section{4. ¿QUÉ ARTíCUlOS NO DEBIERAN ESTAR EN EL DUECh, SEGÚN SUS PROPIAS ESPECIFICACIONES?}

Aunque dicen que lo que abunda no daña, voces como ampalagua, aportillaje, arranquear, bartender, marcatorio, maremoteado, pelucar, potolear, ramplonizar, punearse, rectorábile, viejujaje, ¿pertenecen al léxico usual del dialecto chileno?

También pareciera atentar contra el carácter diferencial del DUECh el que su batería de contrastividad (un conjunto de diccionarios generales), haya incluido una serie de voces del español estándar que, a nuestro entender, no tienen características de uso suficientes como para considerarlas regionalismos: betarraga, convidar, gutapercha, interiorizar, lavavajillas, marginalidad, paja (1), pelagatos, pendón, pijama, sosegar...

En Dar margaritas a los chanchos la definición del DUECh ("Realizar una acción inútil, que no rendirá fruto”) no parece la más adecuada. El sentido es “entregar algo valioso, fino, delicado a quien no es capaz de apreciarlo". La frase no es un dicho chileno ni mucho menos. Aparece en el Evangelio según San Mateo (7:6). Es la mitad de la cita: "No déis cosas santas a los perros, ni echéis vuestras margaritas a los cerdos". "Hablar contigo es echar margaritas a los cerdos" es un verso de la canción de Ana Belén "Margaritas a los cerdos”. Habría que agregar que margaritas no se refiere aquí a las flores así llamadas sino a "perlas". La inclusión en la cita del americanismo chancho en lugar de cerdo o puerco no justificaría su inclusión en el DUECh.

Asimismo parece discutible la inclusión de varios artículos del DUECh. La tecnología informática permite disponer de corpus cada vez más extensos. Es una gran ventaja, pero a la vez puede convertirse en un problema manejar bases de datos lingüísticos con millones de documentaciones. No todo lo que está documentado tiene méritos como para ser incorporado en un diccionario dialectal. Las creaciones individuales sin respaldo social no debieran incluirse. El lexicólogo y el lexicógrafo deben discernir qué 
unidades pueden considerarse incorporadas al dialecto. No toda ingeniosa ocurrencia de los redactores de La Cuarta o de The Clinic debe encontrar acogida.

No siempre parece haberse presentado la variante o el significado más relevante. Para "procurarse complicaciones innecesarias", la expresión usual es buscarle el cuesco a la breva. No aparece en el DUECh. Incluye, en cambio, buscarle los cuescos a las brevas, muchísimo menos conocida. Buzo no parece ser sinónimo de "pantalón deportivo”. Todavía se usa para una vestimenta de trabajo de tela fuerte que consta de camisa y pantalón en una sola pieza.

¿Deben incluirse los adverbios terminados en -mente? Por lo general, no se consideran, salvo que tengan alguna característica especial, no previsible, alguna irregularidad, algún significado singular. En el DUECh encontramos cartuchamente, deducible de cartucho; mariconamente, de maricón; patudamente, de patudo; siúticamente, de siútico; calentonamente se justifica aún menos, ya que calentón aparece en el DRAE como “caliente (lujurioso)”; chuecamente, impajaritablemente.

\section{5. ¿¿UÚ FALTA EN EL DUECh?}

\subsection{Marcas}

No se incluye ninguna marca de valoración social positiva frente a vulgar, podría ser prestigioso, como en el Diccionario de americanismos (Asoc. de Academias 2010). Euf no es una valoración social.

Como marcas cronológicas se usan obsol. e hist.: faltaría tal vez alguna marca para las voces de creación o introducción reciente. No en todos los casos se ponen las marcas correspondientes. Así, por ejemplo, cult. para gatopardo, gatopardismo, calendarizar, agendar, organizacional, portaliano.

No basta la marca de estilo espon. para caracterizar unidades léxicas como mascar chicle: "Llevar metida entre las nalgas parte de una prenda que cubre la pelvis"; echar el portón abajo: "Quitar la virginidad”.

\subsection{Entradas}

Faltan muchísimas entradas y esto no debe de extrañar: suele ser así. ¿Son importantes las omisiones? Un listado amplio excedería los límites de un artículo como éste. Me limitaré a señalar como muestras algunas unidades léxicas que podrían incluirse, siempre que realmente tengan un valor diferencial. El que no aparezcan en el DRAE no indica necesariamente que no pertenecen al español estándar y el que aparezcan tampoco es una garantía de lo contrario.

Han quedado fuera del DUECh lexemas en extremo relevantes para la vida social y política de nuestro país en los últimos decenios, que incluyen los gobiernos de González Videla, Ibáñez del Campo, Alessandri Rodríguez, Frei Montalva, Allende, la dictadura militar de Pinochet ${ }^{11}$, la vuelta a la democracia con Aylwin, Frei Ruiz

1 Muy prolífico para la creación de neologismos como apremio ilegítimo, parrilla, una siniestra máquina de tortura; vendepatrias y humanoides, los opositores. Los exonerados políticos siguen presentes: "la base de datos del registro de exonerados políticos que contiene 157.039 expedientes” (C2 28-10-2011). Para las innovaciones léxicas 19731990, vid. Sáez Godoy (1990) y/o Sáez Godoy (2002). 
Tagle, Lagos, Bachelet y Piñera. Son voces de gran difusión sin restricciones de uso. El controvertido (sistema) binominal ${ }^{12}$, creado para la llamada democracia protegida, ha permitido que se repartan el poder sólo dos conglomerados o referentes políticos ${ }^{13}$, dejando fuera a las minorías y, junto a la invención de senadores vitalicios, senadores designados y senadores institucionales, ha permitido la mantención del legado dictatorial. Los partidos tienen unos operadores políticos cuya misión es conseguir el apoyo de la cada vez más desencantada y escéptica señora Juanita — que representa a la gente común y corriente, a la gente de a pie- traducido en votos blandos o, mejor aún, votos duros. Para ello se trabaja puerta a puerta. La práctica del cuoteo, el reparto de los cargos públicos entre los cuatro o dos partidos de gobierno, convierte a las reparticiones públicas en feudos.

Por una razón de equilibrio y para que nadie se sienta discriminado, si se incluyen pinochetista (y pinochetismo) y udi (acrónimo de Unión Demócrata Independiente, partido de derecha gobernante, heredero del pinochetismo), también debieran registrarse pepedé (miembro del Partido por la Democracia), rádico, radical (y radicalismo), del Partido Radical de Chile, humanistas (del Partido Humanista, de centro izquierda, rogelios $^{14}$, la Jota $^{15}$, todos profundamente 'antipinochetistas' y de oposición al gobierno de S. Piñera, partidos en cuyo seno suelen coexistir, más o menos armónicamente, varias sensibilidades (tendencias) internas. Por ejemplo, chascones ${ }^{16}$ y guatones en la DC.

En el DUECh se registran allendista y pinochetista y se olvidan bacheletista, laguista, freísta (que alude a los partidarios de Frei Montalva y de Frei Ruiz Tagle), aylwinista, alessandrista, ibañista y a los seguidores de otros líderes, muy pocos, como alvearista, lavinista, girardista. Por su parte, la banca chilena, salvada de la quiebra gracias a capitales del Estado, se ha convertido en una de las más sólidas del mundo. En el otro extremo están los 785 niños (entre 12.423 ciudadanos) que, como los perros vagos, viven en situación de calle ${ }^{17}$. El último terremoto y maremoto agravó el problema de la vivienda, se necesitan más soluciones habitacionales ${ }^{18}$ y casetas sanitarias. Los bancos reclutan deudores jóvenes incluso dentro de los campus universitarios y el llamado crédito solidario ${ }^{19}$ para financiar estudios superiores ha

12 "El binominal la lleva. Todos los políticos lo denuncian” (A3 24-10-2011). Su eliminación ha sido planteada tanto por partidarios del gobierno: "Ossandón: Fin de binominal y lista única de consenso (...) la propuesta de poner fin al sistema electoral binominal” (C2 11-9-2011), como, naturalmente, por la oposición: "El PC solicita a La Moneda cambiar el Binominal (...) modificar el actual sistema binominal de elecciones" (C6 10-9-2011). Las citas con este formato son de El Mercurio de Santiago (cuerpo, página y fecha).

13 “'Debe crearse un referente político más amplio’ Jaime Gazmuri” (C2 13-9-2011). "La creación de un nuevo referente con fuerzas opositoras” (C2 17-9-2011).

14 “...Quiere ser médico, se hizo rogelio en Chile” (Cuarta 1, 23-9-2011).

15 “Juventudes Comunistas”: "Vallejo y ex dirigenta (...) estrenan nuevos roles en las JJ.CC. El Comité Central de la 'Jota' analizó el estado de las movilizaciones estudiantiles (...) Cariola fue elegida ayer como nueva secretaria ejecutiva de la 'Jota' (...) El pleno de la ‘Jota' efectuado ayer...”' (C4 10 4-10-2011).

16 “...el senador Mariano Ruiz Esquide lideró una reunión en la que estuvieron representantes del ala 'chascona' de la DC”. (C2 18-10-2011).

17 “.../la perrita Chasca/ fue adoptada por Ana Gutiérrez. Antes estaba en situación de calle” (Cuarta 21-8-2011).

18 “En 2010 y 2011 hemos entregado 400.000 soluciones habitacionales, incluyendo todos los subsidios” (C6 11-10-2011).

19 “...110 000 deudores morosos de crédito solidario” (Cuarta2 9-10-2011). 
significado un endeudamiento intolerable para las familias y cuantiosas utilidades para la banca (y con aval del Estado).

Una familia léxica ha alcanzado una enorme difusión (Chile tiene 6 millones de deudores): repactar, repactación, repactado ${ }^{20}$. La repactación de las deudas del retail sin consentimiento de los afectados se tradujo, además de intereses usurarios, en la falsificación de balances y en el mayor escándalo financiero de los últimos años. Puso en relieve algunas de las solapadas prácticas del crédito para lucrar en perjuicio de los más pobres e indefensos. Como vemos, también en Chile tenemos suficientes motivos para sentirnos indignados.

Uno de los cambios profundos que hizo el gobierno militar que se han reflejado en el léxico fue la municipalización de la educación pública, la entrega de los establecimientos fiscales a los municipios. Su rotundo fracaso ha provocado fuertes movimientos ciudadanos que exigen desmunicipalizar, desmunicipalización de la educación, lo que prácticamente no tiene oposición, incluso están de acuerdo los propios alcaldes (hoy también llamados ediles ${ }^{21}$ ). Las vallas/ barrera/ rejas papales ya no sirven para contener las multitudes.

A partir del gobierno militar se hizo habitual una constante exhortación a emprender (uso intransitivo) y a todo tipo de emprendimientos. En educación ${ }^{22}$ se ha apoyado a los establecimientos privados, en desmedro de los públicos. Sin embargo, legalmente, las universidades no deben tener fines de lucro. Los emprendedores en este campo, siempre imaginativos, encontraron rápidamente un subterfugio: crearon sociedades espejo ${ }^{23}$ ad hoc para traspasarles las utilidades que posteriormente se reparten los mismos dueños.

La baja calidad, el lucro en la educación, han motivado las mayores movilizaciones estudiantiles de la historia que suelen terminar en mesas de diálogo ${ }^{24}$, mesas de trabajo ${ }^{25}$ o mesas técnicas. Retomar $^{26}$ y retomas ${ }^{27}$, recalendarizar ${ }^{28}$ y recalendarización ${ }^{29}$, reagendar son actividades que se han hecho habituales en los establecimientos de educación superior y secundaria.

\footnotetext{
20 “...el retailer detalló que las repactaciones de Presto son ofrecidas a clientes con mora entre 30 y 180 días y se les exige un abono inicial. La cartera no repactada de Presto asciende a \$267.804 millones (...) los repactados totalizan 48.726 clientes por un monto de $\$ 37.000$ millones” (B5 28-9-2011).

21 "los alcaldes de la asociación de municipalidades, comandados por el edil de Vitacura” (C2 30-8-2011). Edil se usaba como sinónimo de regidor, hoy día de concejal.

22 "El Presidente Piñera se mostró proclive a que los privados puedan emprender en este ámbito /educación/” (C3 308-2011).

23 “...la votación que se realizará hoy en torno a la denominada ley de 'sociedades espejo’. La normativa apunta a prohibir que los directores de las corporaciones educacionales sin fines de lucro mantengan vínculos comerciales con la sociedad" (C2 30-8-2011).

24 “...Los debates en las mesas de diálogo serán transparentes” (C2 25-9-2011).

25 “...las negociaciones del gobierno (...) para retomar el diálogo a través de la instalación de una mesa de trabajo...” (C2 25-9-2011).

26 “...no volveremos a intentar retomar los recintos...” (Cuarta, 4, 24-9-2011).

27 “...la retoma 'es un acto de violación ala ley’...” (C11, 24-9-2011). “...tomas y retomas de sedes universitarias...” (Segunda, 2, 13-10-2011).

“ ...los ramos (...) más complicados por la paralización serán recalendarizados para el próximo año...” (C6, 22-9-2011).

29 “...la recalendarización del año escolar...” (C4, 22-9-2011). “/UMCE/... aún no recalendariza el segundo / semestre/...” (Segunda, 4, 3-10-2011.
} 
Por otra parte, un porcentaje de ciudadanos ha salido del clóset, ha defendido públicamente sus derechos y ha logrado que el Presidente presente un proyecto de ley que los favorece.

En las empresas la política de externalización ha significado la desvinculación de muchos trabajadores y una disminución de las remuneraciones. Desvincular, desvinculado y desvinculación ${ }^{30}$ son formas eufemísticas de aludir al hecho de quitarle a alguien su trabajo. Como vemos, queda fuera del DUECh mucho léxico sobre aspectos críticos de nuestra sociedad. Su ausencia podría interpretarse, equivocadamente, como inexistencia o poca relevancia del referente y producir, a la larga, su desaparición de nuestra memoria social.

Por su parte, Farándula en Chile tiene un sentido similar al que el DRAE encuentra en Argentina, Cuba, El Salvador, Venezuela; ya no es simplemente la "profesión y ambiente de los actores", es el "mundillo de vida nocturna". Se ha convertido en un fenómeno mediático muy ligado a la televisión que difunde chismes e intrigas del mundo del espectáculo y sus allegados: actores, bailarinas, cantantes, modelos, animadores, locutores, comentaristas, opinólogos ${ }^{31}$, y se van incorporando futbolistas, políticos ${ }^{32}$. Proliferan programas y secciones faranduleros en televisión, radio, en la prensa escrita. Se habla de una farandulización de nuestra sociedad.

La rápida puesta en marcha del ambicioso sistema de transporte público llamado Transantiago, además de acerar el espíritu de los santiaguinos y confirmar aquello de que el infierno está pavimentado de buenas intenciones ${ }^{33}$, creó una terminología que se extendió rápidamente: tarjeta bip ${ }^{34}$, vías exclusivas, vías segregadas, vías reversibles, hora punta, hora valle, alimentador ${ }^{35}$, bus oruga, estación intermodal, validador... Contemporánea es la incorporación de televías en las carreteras.

Echamos de menos voces como añuñuy, popó ${ }^{36}$ y tilín, que nos acompañaron desde la más tierna infancia, la pilsoca que alegra las convivencias; los patos y los burr(it)os que ayudan a los enfermos. El pintor prefiere las tinetas, más económicas: el gásfiter no usa cotona, instala vanitorios y maneja flexibles y colas de chancho. Algunos oficios tradicionales se llaman de otra forma y han aparecido algunos nuevos: asesora del hogar, trabajadora de casa particular, trabajadora sexual, estriptisera (S.) o striptisera (S.), chatarrero, teatrista, vitrinista, reponedor, mozaico. ${ }^{37}$

\footnotetext{
30 “...el luqueo interno permitió la desvinculación del autor de los disparos (...) totalizando 9 los funcionarios desvinculados” (Cuarta, 2, 31-8-2011).

31 "Se supone que tengo un rol de opinólogo, pero lo que hago ahí es humor" (Cuarta, 14-10-2011). Se habla incluso de opinología.

32 "La farándula criolla no podía faltar en tamaña fiesta del lolerío /concierto de J. Bieber/ (...) el ruliento Leonardo Farkas (...), Myriam Hernández, Iván Zamorano, Vasco Moulian, Eduardo Cruz-Johnson...” (Cuarta, 30, 16-10-2011).

33 “Es una mala palabra, Transantiago, es una muy mala palabra”. (Michelle Bachelet, junio de 2007).

34 “A falta de tarjeta bip le tenían un helicóptero...” (Cuarta, 30, 16-10-2011).

35 "Veolia se queda con el alimentador de la zona C (...) Juan Pinto y sus socios se adjudican los alimentadores I (...), J (...) y H...” (C15, 1-10-2011).

36 "nalgas" (infantil). Incluso en el DRAE aparece como propio de Chile. "Por respeto a nuestros lectores que no dicen ni popó esta es la traducción del poema...” (Cuarta, Dep., 4, 24-10-2011).

37 “La gente se sorprende. Aplaude y vitorea al mozaico...” (Cuarta, 2, 11-10-20.11).
} 
Nuestro dialecto crea, pone de moda y olvida diversas formas de caracterizar al prójimo, casi siempre críticamente (el elogio no es nuestro fuerte): espinita, florero, autorreferente, masoca, pasado pa' la punta, mala onda, tira p'abajo, pisacallos, hiperventilado, cachurero, cortoplacista, cara de poto, manilargo ${ }^{38}$, choriflái...

\subsection{Acrónimos, siglas y otros}

Por otra parte, habría que incluir algunos acrónimos y siglas de uso frecuente: Core (Consejo Regional), core (consejero regional) ${ }^{39}$, deté o $D T^{40}$ (director técnico) ${ }^{41}$, tricel (tribunal Calificador de Elecciones), GAP ${ }^{42}$ (Grupo de Amigos Personales del Presidente Allende, que ya puede considerarse histórico), Samu ${ }^{43}$ (Servicio de Atención Médica de Urgencia), Sapu ${ }^{44}$ (servicio de atención primaria de urgencia), UF (Unidad de Fomento), uti (Unidad de Tratamientos Intensivos) ${ }^{45}$, etc.

También podrían agregarse lexías usuales en aposición S+S como buque insignia, camión aljibe, grúa horquilla, coche comedor, coche dormitorio, hora valle, idea fuerza, operación rastrillo, operación peineta, robo hormiga, tapa rosca, sociedad espejo...; S+Adj: caseta sanitaria, red social...; compuestos V+S: quitapenas (local), cazanoticias, calientacamas, cubresuelos, cuentachistes, pistola cuentalitros, pasapelotas, tapagoteras.

\subsection{Locuciones verbales}

Una gran cantidad de locuciones verbales muy habituales del español de Chile no deberían estar fuera del DUECh: apretar cachete, arrastrar el poncho, chuparse los bigotes, dar un paso al lado/costado, dar un portazo, echarle con l'olla, empinar el codo, (d)entrar a picar, entregar las herramientas, estar en otra, hacer chupete, hacerse el loco, ir en la parada, irse al sobre, mandarse un numerito, mirar pa'l lado, pasar la aplanadora, patear el tablero, patear piedras, pegarse el pollo/ el broiler, pelar forros, pisar callos, poner paños fríos, quedar con el ombligo parado, repetirse el plato, repetirse los espárragos, sacar pecho, sacar(se) la cresta, tener una car(it) ta bajo la manga, tener onda con alguien, tirar la toalla, valer hongo...

"ladrón”.

39 “...firma envío de ley que establece mecanismo de elección directa para cores (...) proyecto de ley que establece, (...), que los consejeros regionales (cores )...” (C2, 12-9-2011).

40 “...cualquier DT le desearía /a Alexis Sánchez/ buena suerte y que la rompa...” (Cuarta, 24, 29-10-2011).

41 “Luis Mena, el tricampeón albo, quiere jugar un par de años (...) y luego ser deté de detés” (Cuarta, 8, 28-10-2011).

42 La sigla sigue viva en la memoria popular: "GAC o Grupo de Amigos de Camila Vallejo le cuidan hasta la sombra a la líder estudiantil” (Cuarta, 15-9-2011).

43 “La mujer pidió ayuda y personal del Samu llegó al lugar, pero ya era muy tarde”. (Cuarta, 4, 21-10-2011).

44 “...se le intentó controlar y fue derivado al Sapu de Concón donde se le brindaron las primeras atenciones médicas” (E. M. de Valparaíso, 4. 3-11-2011).

45 Incluso en uso metafórico “El puente en camino a Valpo está en la UTI” (Cuarta, 12, 31-8-2011). 


\subsection{Faltan acepciones, homónimos y variantes}

Es frecuente la omisión de algunas acepciones, homónimos o variantes usuales. Algunos ejemplos:

Parar la cola "morir". Habría que agregar "irse abruptamente”.

En block aparece sólo el significado urbanístico-arquitectónico de un tipo de edificio de departamentos, pero no los de "cuerpo de un motor", ni el de "conjunto de pliegos de papel para dibujar o tomar notas”.

Caleta, además de "mucho”, es “casa clandestina, escondite, refugio”.

Cola de chancho o colechancho, "persona traicionera”, también denomina una conexión de esa forma que usan diversos técnicos.

Pellet, "Cápsula empleada en el tratamiento de alcohólicos”; más usual es el uso metonímico del anglicismo para alimento de perros, gatos y para los pequeños cilindros de combustible de madera: "LICITACIÓN (U...) FÁBRICA DE PELLETS DE MADERA (...) PRENSA DE PELLETS (...) PRENSA PELLETERERA...” (Tercera, 12. 10-10-2011).

Pepa se emplea corrientemente como un sinónimo coloquial y festivo de "ojo": “Con las pepas bien abiertas están los chistólogos que más hacen reír en el terruño por el Copihue de Oro 2011...” (Cuarta, 14-10-2011). El DUECh no lo registra, pero incluye "semilla”, “tumor de las gallinas”, “droga”, "gol”.

Es muy frecuente en la competencia por atraer compradores promocionar un combo, una oferta comercial de rebaja por un conjunto de varios productos.

Dama, además de "colaboradora de una institución benéfica", es una fórmula de tratamiento que pretende ser formal y fina, propia del personal de servicio, camareros de restaurantes y hoteles, cuidadores de autos, vendedores ambulantes.

Entaquillado "de buena calidad". He encontrado otros significados: "bien vestido", "erguido, de personalidad fuerte”, probablemente derivado de taquilla "clavito que usan los zapateros".

Burro o burrito es también una armazón con ruedas en la que se afirman los enfermos para poder caminar.

Toperoles, además de "Pieza cónica pequeña adosada a la suela de un calzado...”, ha pasado a denominar el calzado de fútbol, pars pro toto.

Además de los anglicismos blade y blay ("globo de goma que va al interior de los balones") hay documentadas otras variantes que no figuran en el DUECh: bladder, blader, blari.

Mariconear en sentido recto es “actuar como maricón (homosexual)”. La acepción no aparece en el DUECh.

Pancora tiene la variante apancora, que debería ser incluida como entrada, aunque figure en el DRAE.

Falta la variante pichoga de pichoa, probablemente la más frecuente.

Potrero no es sólo un "terreno extenso desprovisto de vegetación”, con frecuencia es en Chile "terreno cercado para sembrar o con pastos para alimentar animales".

Rajado, "a mucha velocidad" y "generoso", significa también "suertudo", derivado de raja 2, "suerte".

Conchelalora no sólo es interjección o locución interjectiva: “....el UARS cayó a la conchelalora en África” (Cuarta, 6, 21-10-2011). 


\subsection{Variantes oral y escrita}

Una de las numerosas decisiones que debe tomar el lexicógrafo es incluir o no la variante oral, la escrita o ambas. Ningún chileno dice cachada, peor es nada, patitas para qué te quiero; las variantes que todos usamos son cachá, pioresná, patita 'pa'qué te quiero. El DUECh incluye sólo las primeras, pero no es una práctica consecuente, porque también aparecen peoneta y pioneta, concha de su madre y conchesumadre y en el artículo guindado se advierte que "Suele pronunciarse / guindao/, y a veces incluso se escribe 'guindao'”.

\subsection{Unidades léxicas}

Falta indicar con mayor precisión la relación entre las unidades léxicas y la forma base de la cual derivan. En muni la definición comienza, aunque sin mayores aclaraciones, con Municipalidad; en celu, con celular; en repre, con represión; en depa y depto, con departamento; en ril, con residuo industrial líquido; mandarse al chope, mandarse al pecho. De este modo, implícitamente, se le señala al lector que el contenido semántico fundamental de la voz que se analiza es el de la unidad léxica base, a menudo acompañado de algunas connotaciones. Normalmente no se indica que se trata de acortamientos, de abreviaciones, de acrónimos; salvo en las inversiones, como rati o broca cochi en las que se señala que provienen de tira y cabro chico, y la generalización de un nombre propio (confort). Es una práctica adecuada, aunque debería ser más explícita. Sin embargo, tampoco es consecuente. Muy a menudo en las definiciones se omiten estas relaciones, que son clave para entender el significado de la lexía; y ni siquiera se menciona la forma base de un derivado o de un acortamiento, la forma completa de una sigla o una expresión. Algunos ejemplos:

En malacué o malacue debería indicarse que procede de una fusión y acortamiento de mala cueva, que esconde a cueva, sumamente ordinaria. Lo mismo sucede con aprecué que no se entiende sin una referencia a apretar cueva. Ambas aparecen en el DUECh, pero sin establecer ninguna relación entre ellas.

Muy semejante es el caso de mansaca $^{46}$ : no se informa que es una fusión y acortamiento de mansa cagada, lo que explica la definición de "Situación caracterizada por la confusión y el desorden”.

Nica, “de ninguna manera”, al ignorar la base ni cagando, falsea por omisión la valoración y el estrato social que se le asigna a la unidad léxica.

Tampoco se relacionan Paganini y pagar; peni y Penitenciaría; por su poto y por supuesto; aparecen peñizco, piñizco, peñizcón sin ninguna alusión a pellizco; en al tirante no se remite a al tiro (ni se hace referencia a la expresión al tirante, $m i$ comandante).

Puede parecer extraño que califa signifique "muy propenso a sentir deseo sexual” y que huemul equivalga a "tonto". ¿Es tal vez el patriótico huemul un animal reconocidamente estúpido? El lexicógrafo debería señalar que se trata de deformaciones eufemísticas: califa y Californla, de caliente; huemul, de huevón;

“ADELANTARON LA HORA Celulíticos ‘pillos’ dejaron la mansaca” (Cuarta, 3, 10-10-2011). 
miércoles, de mierda...

Tampoco en lancear y lanceo se establecen relaciones con lanza.

Parece conveniente señalar que hay un ¿y vos? encubierto en expresiones para indicar que lo que un interlocutor le critica a otro, en rigor, también podría aplicársele a él con toda razón: ¿Y Bosnia? ¿Y Boston? Albornoz.

Tampoco se señalan las formas bases de otras deformaciones paranomásicas: durazno, de duro; galucha, de galería, poblete, de pobre ${ }^{47}$.

Debería indicarse que de cola, “cóccix”, se pasa a cola "homosexual” y, por deformación eufemística, a colipato, colihuacho, coliza, colizón (y de este por derivación colizonear)...

En tifa no se indica que se trata de un acrónimo de Tarjeta de Identificación de las Fuerzas Armadas.

En suple no se señala que es un acortamiento de suplemento y en impeque no se establece la relación con impecable.

Tener del año que le pidan "Ser muy tonto" se explica por un huevas elíptico: Tener (huevas) del año que le pidan. Del mismo modo, tirárselas debiera remitirse a tirarse las huevas que explica el enclítico.

\subsection{Falta completar algunas expresiones}

Otras omisiones afectan a una mejor comprensión de las unidades léxicas.

El artículo capitán Araya "Persona que dirige a otros en determinada actividad, sin comprometerse suficientemente" es poco claro. Sin duda, se entendería mejor con la inclusión de alguna versión de la expresión completa: "El capitán Araya embarca a su gente y él se queda en la playa". También quedan truncas Mala cueva, dijo el conejo. Le falta el colofón "y se cambió de hoyo" y Calabaza, calabaza (cada uno pa'su casa)...

\subsection{Falta completar definiciones}

Algunas definiciones se quedan en el hiperónimo sin los especificadores que permiten distinguir entre los hipónimos. Causeo no es cualquier comida, una liebre no es cualquier autobús, sólo algunas fiestas pueden calificarse de farras o remoliendas. Veamos esto más en detalle.

La definición de causeo es muy poco específica, prácticamente inútil: “comida, sustancia que se ingiere para alimentarse”. Sería necesario incluir algunas notas definitorias del causeo, tan importante para nuestro pueblo que Pablo de Rokha sostenía que Chile es un largo causeo entre el mar y la cordillera. Entre los semas podrían estar "comida fría”, "los elementos fundamentales son algún tipo de carne, patas de cerdo o vacuno, lengua, cabeza de cerdo o de cordero... y cebolla”, "todo debe estar picado, mezclado y aliñado”, "suele incluir también ají, tomates, cilantro, huevos duros, aceitunas, todo picado”, "pertenece a la cocina popular”.

Tampoco es suficiente indicar que liebre es "autobús de transporte colectivo urbano”. Habría que diferenciarlas de micros, buses, colectivos, minibuses, góndolas.

47 No aparecen algunas tan difundidas como federica $<$ fea, libreta $<$ libre, liztaylor $<$ listo, precioso $<$ preso; riquelme

$<$ rico, ricarda $<$ rica. 
También en medio pollo la definición es excesivamente general: "Empleado de baja categoría..." Falta una característica definidora que explica el medio: se trata de quien le hace el trabajo por media paga a quien está contratado oficialmente para realizarlo y recibe para sí el sueldo entero sin mayor esfuerzo. El sistema era característico de las faenas portuarias en Valparaíso.

"Participar en fiestas u otro tipo de eventos" no define suficientemente a farrear. Un cumpleaños infantil con globos, serpentinas, torta y helados es una fiesta, pero en ningún caso una farra (al menos no todavía). Ésta es más bien juerga, parranda, jarana, tiene que ver con trasnoche, bullicio, alcohol...

Son muy generales las definiciones para remoler "Participar en fiestas u otro tipo de eventos de esparcimiento" y remolienda "evento de diversión o esparcimiento". No se trata de cualquier diversión, es propiamente una orgía. En cambio, la definición de casa de remolienda es aceptable "Prostíbulo, establecimiento en que las prostitutas ofrecen sus servicios”. Probablemente diferencias como estas se deben al trabajo descoordinado de redactores de distinto nivel.

La empleada de mano o niña de mano no es una empleada doméstica cualquiera, es la encargada de la limpieza y el orden de la casa, especialmente de los dormitorios, y del planchado; la cocina no forma parte de sus obligaciones.

Mascota, "Persona que dentro de un grupo, recibe un trato especial". Definición excesivamente amplia que precisa de unas restricciones para marcar alguna diferencia con el DRAE.

\subsection{Ausencia de semas importantes en definiciones}

La definición de guardapeos "pantalón ancho que llega a la mitad de la pierna” olvida semas básicos "perneras bombachas”, “ajustados en la parte inferior”. Son los pantalones de golf, los que usaba el Príncipe de Gales, más tarde Eduardo VIII. La mediagua no es mediagua si no es "de techo inclinado de una sola vertiente". En Quiridi, “avaro, mezquino”, son sólo dos aspectos. La voz es equivalente de judio con todas las connotaciones que tiene entre nosotros: "hábil para los negocios, de exagerado amor por el dinero, astuto”. En Kojak no es imprescindible, pero sería muy aclaratoria una referencia a la serie de televisión norteamericana protagonizada por Telly Sabalas como Theo Kojak, un policía incorruptible adicto a estas golosinas.

\section{6. ¿QUÉ PODRÍA CAMBIARSE EN EL DUECh?}

6.1. La locución verbal arrastrar la bolsa del pan apunta a la imagen de una niña cuyos padres la mandan a comprar al almacén y de vuelta a casa, por su pequeña estatura, camina arrastrando la bolsa del pan. Años más tarde, cuando crece, ya no arrastra la bolsa, es mayor y, como tal, puede hacer cosas de grande como tener relaciones sexuales. En suma, arrastra la bolsa del pan la niña de poca edad y sin la contextura física como para tener relaciones sexuales y no la arrastra si ha dejado de ser niña y ya tiene una práctica sexual. Un ejemplo: el líder del CDU alemán Christian von Boetticher debió renunciar en Schleswig Holstein a su candidatura a gobernador, luego que se hizo público que "mantuvo un romance con una pergenia de 16 años, quien todavía arrastraba la bolsa del pan”. (Cuarta 11, 16-8-2011). El equipo 
del DUECh entendió la locución totalmente al revés: “Arrastrar la bolsa del pan (...) Tener edad suficiente para tener relaciones sexuales." 48

Algunas definiciones son imprecisas, ambiguas o erróneas.

6.2. Matar la gallina, según el DUECh, es "masturbarse”. El ejemplo que se ofrece no es claro. Desde hace mucho tiempo es un sinónimo popular de "tener relaciones sexuales”: "Los presos de la cárcel de Chillán se chorearon de tener que matar la gallina con sus parejas en carpas y cuchitriles y decidieron construir una cadena de venusterios muy parecidos a la mansión de un sultán petrolero” (Cuarta 11, 10-8-2011).

6.3. Sólo muy parcialmente, sostenedor es "persona que dirige un establecimiento educacional de nivel básico o medio que, sin ser público, recibe subvención estatal”. El asunto es más complejo. Hay que distinguir, por una parte, entre sostenedores municipales $^{49}$ (municipios, alcaldes) y $\operatorname{privados}^{50}$ (personas naturales o jurídicas); éstos son los dueños de los establecimientos, por lo general, empresarios que lucran con la educación, pero también algunas instituciones religiosas, fundaciones. Por otra parte, están los directores, contratados para dirigir la marcha docente.

6.4. Da la impresión de que las definiciones se armaron para explicar la cita específica documentada. Por lo general, este objetivo se logra. Pero el hablante tiene en su mente un significado general y la cita es sólo una de las múltiples aplicaciones posibles de ese significado, mucho más amplio que un uso particular. El DUECh suele no captar ese significado subyacente y aborda sólo los casos particulares. Un ejemplo: a mandarse al pecho (o mandarse al chope) se destinan tres artículos independientes, lo que indica que para el DUECh no hay una relación estrecha entre estas significaciones; si la hubiera, estarían dentro de un mismo artículo: (1) (que debiera ser la de mayor frecuencia o relevancia) "comer algo con rapidez y entusiasmo”; (2) “derrotar en forma aplastante” y (3) "Poseer sexualmente a alguien”, que se explican por tres ejemplos, uno que alude a una panzada, otro al equipo de fútbol de Til Til y el tercero, a un joven. Parece poco adecuada esta concepción, porque la gama de lo que se puede mandar al pecho es muy amplia: en sentido recto, bebidas $^{51}$, cigarrillos,...; metafóricamente, deudores, clientes, pacientes, cotizantes, consumidores, la legislación; habría que multiplicar los artículos para explicar cada ejemplo que aparezca, en definitiva, no es la mejor solución.

6.5. Las definiciones construidas para explicar el ejemplo, a menudo, tienen un alcance restringido. Un par de casos: Rajar (2) tiene un significado más general que "Huir apresuradamente”. Más bien es "salir, partir apresuradamente”: “...luego de ver el panorama completito /de los problemas urbanos de un cerro de Valparaíso/, Helms rajó hacia la Muni...” (Cuarta, Mi Barrio, 1, 24-8-2011).

\footnotetext{
48 En cambio, el Diccionario de Americanismos (Asoc. de Academias 2010) la define adecuadamente "No haber alcanzado aún una mujer edad para mantener relaciones sexuales”.

49 “...responsabilidad del alcalde, que es el sostenedor del establecimiento...” C11, 24-9-2011.

50 "Piñera suplica por mesa de diálogo: ‘No puedo dejar que los sostenedores pierdan el año’” (The Clinic, 3, 22-92011).

51 “...después de haberse mandado al chope cuatro wiscachos y cuatro mojitos...” (Cuarta 31, 7-9-2011).
} 
6.6. Pato malo no es sólo el "que roba de manera violenta". El significado es mucho más amplio: narcotraficantes, proxenetas, lanzas, delincuentes en general. Similar es el caso de promo, cuyo significado no sólo es "Conjunto formado por una botella de bebida alcohólica y otra de gaseosa o jugo, que se vende a un precio menor al de ambas por separado”. La oferta también puede ser otra, pizzas, por ejemplo: “... estaba (...) esperando que le entregaran una promo $2 \mathrm{x} 1$ de pizzas con queso y pepperoni” (Cuarta, 11, 24-8-2011). Asimismo: las pitanzas, "bromas (...) que se hacen por teléfono”, no son necesariamente telefónicas.

6.7. También es frecuente que algún sema o varios sean discutibles. En beatle no es adecuada la especificación "cubre el torso". En realidad, cubre el torso, los brazos y el cuello, esto último es lo que lo diferencia de otras prendas similares. El significado de al callo más que “de modo directo” parece ser "al detalle, con toda precisión y “a la medida”. Valer callampa es una expresión vulgar que aumentó de golpe su difusión cuando le costó la cartera a un Ministro de Defensa, luego de un agitado intercambio de ideas, con el micrófono que inadvertidamente quedó abierto. La conversación privada se retransmitió urbi et orbi por todos los medios de prensa. Más que "ser de mala calidad” es "no tener absolutamente ningún valor".

Los changos no sólo habitaron "parte del extremo Norte de Chile". Se desplazaban por la costa hacia el Sur. Sus balsas de cueros inflados de lobos marinos las encontramos en Valparaíso.

Marquesa, "Parte de la cama que va tras la cabecera, que sobresale varios centímetros por sobre la altura del colchón”, usualmente designa un tipo de cama baja, con un pequeño respaldo.

Plr es una sigla de "patada en las nalgas, más elegante que "Patada en La Raja”, pero inexacta. La grafía usual es PLR: “Coquimbanos quedaron hinchados tras PLR al deté”. (Cuarta. 21, 31-8-2011).

Mype tampoco es sigla de "Mediana y pequeña empresa...", sino de "Micro y pequeña empresa” (676.078 en Chile el año 2003). Pyme y mype no son sinónimos.

Impajaritable más que "de carácter imprescindible” es más bien "que no puede dejar de suceder”.

Pichanguero “...que juega poco con el resto del equipo”, ese es el comilón, en la jerga futbolística. El pachanguero es el "que por gusto participa habitualmente en juegos de pelota, especialmente fútbol, informales y entusiastas” y “relativo a las pichangas”.

El guindado es un licor elaborado con aguardiente, almíbar y, obviamente, guindas, no cerezas.

En el DUECH pachotada se define por su "obviedad y grosería". Lo primero no corresponde, sería preferible "agresividad, falta de respeto".

Mauloso "embustero". A mi entender, "tramposo”.

Picante más que "poco elegante” es "ordinario, vulgar”.

Tupido y parejo "Con mucha intensidad”, más bien "con suma frecuencia”.

Potifrunci y potijunto no son "excesivamente cursi”, más bien "melindroso", “pudibundo”, “mojigato”, “delicado en extremo”.

El pizarrón no necesariamente “...se adhiere a una pared”.

Lápiz no parece ser el hiperónimo de pluma fuente.

La mujer contratada para encargarse de las tareas de la casa (asistenta, criada, sirvienta o empleada de hogar en el DRAE) ha recibido en Chile diversas 
denominaciones, desde la menospreciada china ha ido ascendiendo en la consideración social: empleada, empleada doméstica, asesora del hogar, trabajadora de casa particular hasta la actual nana. Como asesora del hogar no es una unidad léxica del español estándar ni tampoco está incluida en el DUECh, no debiera formar parte de las definiciones de puertas adentro y puertas afuera. En las definiciones debieran emplearse voces del español estándar o dialectalismos definidos en el diccionario. Así, Nana tiene una carga afectiva que le ha permitido imponerse lentamente y llegar hasta los niveles más formales ("Nanas foráneas tienen mejor nivel educacional que las chilenas" (C10, 17-10-2011), pero siguen usándose sus competidoras: "Nana inventó asalto para desvalijar vivienda de su jefa (...) la PDI estableció que la asesora del hogar que había denunciado el hecho (...) inventó un atraco para sustraer cuantiosas especies (...) la empleada doméstica identificada como Hilda Molina...” (El Mercurio de Valparaíso, 6, 20-8-2011). El DUECh como términos generales registra sólo empleada y nana.

\subsection{Algunas definiciones son innecesariamente complejas:}

Reversa, "Mecanismo que permite hacer que un vehículo avance en dirección a su parte posterior”. Avanzar hacia atrás es retroceder. Es algo irregular la calidad de las definiciones del DUECh.

Recoger cañuela, "Dejar de hacer algo que se esperaba se hiciera” más bien es "retractarse".

\section{CONCLUSIONES}

El objeto de este diccionario, el léxico del español de Chile, es de la mayor importancia lingüística y cultural. Así lo han entendido los especialistas y en el mismo año 2010 se publicaron dos contribuciones importantes: los tomos IX y X de actualización del $D E C h^{52}$, una obra ya clásica de nuestra lexicográfía, y el $D U E C h$ que hemos comentado. Ambas obras han recibido el respaldo de importantes instituciones culturales del país y han hecho un notable aporte para mejorar el conocimiento sobre el estado actual de nuestro léxico.

El esfuerzo de la AChL es encomiable. Formó un numeroso equipo integrado por los lingüistas de su Comisión de Lexicografía y siete colaboradores que tomaron a su cargo la ambiciosa, difícil y pesada tarea de construir un diccionario que hiciera olvidar su intento anterior. Lo lograron en buena medida. El corpus les permitió un gran acopio de materiales; además tuvieron el buen criterio de seguir al DECh y entregar ejemplos en cada artículo, salvo para los gentilicios. Esto permite captar no sólo el contenido semántico de cada unidad léxica sino también su uso real. Por primera vez se aprovechan en forma masiva textos que circulan por Internet en blogs y foros. La edición es de fácil consulta, está dirigida al lector corriente y no abusa de tecnicismos. La estructura de los artículos permite una descripción suficiente de las circunstancias de uso de cada unidad léxica.

Este diccionario está concebido no como un producto final sino como una obra que “empieza su andadura”, “modular” y “perfectible”, y se invita a los destinatarios,

2 Reseña en Sáez Godoy (2011). 
a los profesores en particular, a hacer observaciones para mejorar la calidad del $D U E C h$. Este artículo responde a esa amplia invitación. Es un diccionario con nuevas fuentes, nuevos aportes, accesible y asequible. Por cierto, algunos aspectos deberán mejorarse. Hemos presentado sólo algunas muestras. Aplicación aleatoria de algunas de sus prácticas lexicográficas; definiciones erróneas, muy generales, incompletas, sin especificadores imprescindibles o en extremo particularizadoras y estrechas; semas que no corresponden o se omiten. Parece necesaria una revisión profunda antes de publicar un nuevo módulo. Con certeza, la experiencia adquirida les permitirá, además, mejorar la redacción de los artículos.

El análisis del corpus ha dejado fuera gran cantidad de unidades léxicas usuales y muy difundidas, tanto coloquiales como formales. Habrá que ampliar el corpus o aprovecharlo mejor. He puesto a consideración algunos posibles agregados que me han parecido más necesarios para disponer de una eficaz "herramienta de consulta para comprender textos escritos y orales" y talvez incluso para "producir textos en lengua materna”.

La lexicografía chilena dispone de dos repertorios actuales: los 10 tomos del DECh y este primer volumen del DUECh, que recién comienza. Gaudeamus igitur.

\section{OBRAS CITADAS}

Academia Chilena de la Lengua. 1978. Diccionario del Habla Chilena. Santiago: Edit. Universitaria. 280 pp.

Academia Chilena de la Lengua. 2010. Diccionario de uso del español de Chile. Santiago: MN Editorial Ltda. 965 pp.

Asociación de Academias de la Lengua Española. 2010. Diccionario de americanismos. Lima: Santillana Ediciones Generales, S. L. 2.333 pp.

Carrillo Herrera, Gastón. 1981. “Diccionario del Habla Chilena” en Romanische Forschungen 93 1/2: 216-222.

Matus Olivier, Alfredo. 2010. "Prólogo a El Diccionario de uso del español de Chile (DUECh)" en Academia Chilena 2010: 5-10.

Morales Pettorino, Félix y Oscar Quiroz Mejías. 1983. Diccionario Ejemplificado de Chilenismos. Estudio Preliminar. Santiago: Ediciones del Consejo de Rectores de las Universidades Chilenas. 50 pp.

Morales Pettorino, Félix et alii. 1984-1998. Diccionario Ejemplificado de Chilenismos y de otros usos diferenciales del español de Chile (DECh). Valparaíso: Academia Superior de Ciencias Pedagógicas, T. I, 1984; T II, 1985; U. de Playa Ancha de Ciencias de la Educación, T. III, 1986; T. IV, 987; U. de Playa Ancha - U. Tecnológica V. Pérez Rosales, T. V, 1998.

Morales Pettorino, Félix et al. 2006. Nuevo Diccionario Ejemplificado de Chilenismos y de otros usos diferenciales del español de Chile (NDECh). Valparaíso: Edit. Puntángeles. 3 tomos.

Morales Pettorino, Félix. 2010. Nuevo Diccionario Ejemplificado de Chilenismos. Edición refundida y actualizada. Suplemento. Valparaíso: Edit. Puntángeles. T. I, 1.243 pp. T. II: pp. 1.245-2.321 (tomos IX y X del DECh. IV y V del NDECh).

Sáez Godoy, Leopoldo. 1982. "Algunas observaciones sobre el diccionario más reciente del español de Chile: el Diccionario del Habla Chilena (DHCh)” en Estudios Filológicos 17 (1982): 111-124.

1987-1988. “A propósito del Diccionario del Habla Chilena”. En Literatura y Lingüistica 1: 107-127. 
.1990.“Novedades en el español de Chile (1973-1989) (Neologismos en el léxico de la vida sociopolítica y de los derechos humanos)”. Literatura y Lingüistica 3: 117-151.

. 2002. El español de Chile. La creatividad lingüística de los chilenos .Santiago: Edit. BACH - Colección Idea (USACh). 197 pp.

2011. "Reseña de Nuevo Diccionario Ejemplificado de Chilenismos. Edición refundida y actualizada. Suplemento" en RLA, Revista de Lingüistica Teórica y Aplicada 49 (1): 169-173. 